\title{
AVALIAÇÃO: CONCEPÇÕES SUBJACENTES AO OLHAR DO-DISCENTE
}

\author{
Apresentação: Relato de Experiência \\ José Ailton Dias da Silva ${ }^{1}$; Lindinalva Queiroz ${ }^{2}$.
}

\section{Introdução}

A avaliação é um processo natural, que deve ser interiorizado pelo professor para que sua prática seja norteada pelos pressupostos que esta delimita. O processo avaliativo como, se expressa, deve estar preocupado com o desempenho durante o caminho da aprendizagem. Desta maneira evidencia-se que o ato avaliativo não deve ser confundido com um fim que apenas serve para registrar e classificar. Nessa direção, este estudo propõe uma reflexão e análise de como ocorre a avaliação escolar, partindo de estudos teorizados e vivência da prática.

Sabe-se que a avaliação passa por diversas etapas ao longo da história, sendo encarada por de forma técnica e mecanizada. Por muito tempo se trabalhou dentro das escolas com uma perspectiva de avaliação engessada à luz de modelos repressivos. Hoje, com as reflexões e inquietações por parte daqueles que fazem a educação (gestor, coordenador, professores, alunos, pais de alunos) e amparados teoricamente, trouxeram para a escola um novo olhar sobre a forma como o conceito de avaliação é vivenciado no cotidiano escolar. Tais colocações nos fazem perceber que este processo ainda necessita de muitas mudanças para que se atinja ou ao menos se eleve o índice de planejamento avaliativo como forma de melhoria da qualidade da educação.

PALAVRAS CHAVE: Avaliação. Reflexão. Ensino e Aprendizagem. Escola

\section{Apresentação}

Diante do exposto, ressaltamos que este estudo emergiu no contexto da disciplina de

1 Aluno da Graduação do Curso de Pedagogia - FACOL (E-mail: ailton_10anos@hotmail.com)

2 Professora Orientadora (E-mail: lindyqueiroz@yahoo.com.br) 
Avaliação em Educação na Instituição de Ensino Superior Faculdade Escritor Osman da Costa Lins - FACOL localizada no município de Vitória de Santo Antão/PE. Assim, com os estudos realizados dentro das perspectivas educacionais vimos que a avaliação é uma das áreas que deve ter uma total atenção mediante a prática cotidiana presente dentro das escolas.

Nesta seção iremos tratar de uma análise às questões que permeiam a avaliação, seus níveis e como estão inseridos e/ou não, no fazer docente dos professores. Neste seguimento temos como objetivo: Analisar as concepções subjacentes do olhar do-discente sobre a avaliação aplicada no contexto escolar. Nesta perspectiva, o trabalho apresentado vem estruturar-se em uma sequência fundamentada em autores contemporâneos que nos possibilitam repensar a avaliação como prática efetivada dentro da escola. Por meio de entrevista e coleta de dados pudemos ter o contato direto com a realidade vivenciada no cotidiano escolar.

\section{Relato de Experiência}

Para darmos início a esta discussão vamos partir de alguns paradigmas que permeiam a educação e o processo avaliativo inserido dentro das escolas. Partindo do principio de que o processo de avaliação perpassa por diferentes etapas, refletir sobre a forma como este se deu e vem se dando até hoje é compreender que assim como a autonomia e a democracia são processos que estão em constantemente construção dentro de todas as escolas dentro nosso país. Neste contexto, corroboramos que educar para a emancipação é a função social que a escola deve exercer enquanto formadora de conhecimento e novos pensadores. Desta forma, a avaliação contribui significativamente servindo como norteadora das tomadas de decisões e caminhos a serem percorridos. Haja vista, a avaliação se faz presente em todo o cotidiano das pessoas, uma vez que "comparamos", "julgamos", estamos avaliando a conduta de uma determinada situação e/ou comportamento, "seja através das reflexões informais que orientam as frequentes opções do dia-adia, ou formalmente, através da reflexão organizada e sistêmica que define a tomada de decisões" (DALBEN, 2005, p. 66).

A avaliação tem suas interfaces, e dentro do contexto escolar está sempre associada a um objetivo ou meta que se almeja chegar. Assim, de forma sistematizada ela vem cumprir as exigências de um determinado conceito trabalhado em sala de aula. Como afirma Caldeira (2000):

“A avaliação escolar é um meio e não um fim em si mesma; está delimitada por 
uma determinada teoria e por uma determinada prática pedagógica. Ela não ocorre num vazio conceitual, mas está dimensionada por um modelo teórico de sociedade, de homem, de educação e, consequentemente, de ensino e de aprendizagem, expresso na teoria e na prática pedagógica.” (p. 122)

O autor deixa evidente que a avaliação está associada a uma determinada estrutura amarrada. Não acontecendo de forma solta e sem objetivos, mas estruturada na intenção de atender a objetivos e norteada por conceitos que vão de encontro a um modelo teórico de sociedade e que esta organização está pautada no encontro da teoria e prática pedagógica. Existem diferentes concepções a cerca de como a avaliação é feita e de como ela deveria ser, nos deixando conscientes de que a concepção e prática do professor é que determina a forma como a avaliação é vivida.

Por não ser um fim em si mesma e por fazer parte de um processo, não deve se deter a meramente registrar e classificar os alunos por meio de testes e provas. Estes devem ser vistos como um dos diversos instrumentos que o professor deve se utilizar para avaliar seus alunos. Uma coisa que os professores devem ter bem clara quanto à forma como avaliam é justamente a de não esperar ter como retorno apenas aquilo que é passado para seus alunos, pois o que deve ser priorizado é a construção do conhecimento que nem sempre está arraigado num tradicionalismo em dar como devolutiva aquilo que o professor tem como planejado e/ou previsto. A orientação faz parte do processo de avaliação e confere a seus alunos a possibilidade de melhor encaminhar a aprendizagem, uma vez que esta ação mostra que eles são importantes e que há uma preocupação quanto ao seu desempenho e desenvolvimento. Como afirma Luckesi (1996) "Seja pontual ou contínua, a avaliação só faz sentido quando provoca o desenvolvimento do educando.” (p.15). Desta forma, compreende-se que a orientação deve estar objetivada na aprendizagem do aluno para que a avaliação o atinja às metas estabelecidas.

Recorrendo as diferentes facetas da avaliação e como ela acontece dentro das escolas. Nos níveis de avaliação estão declaradas três modalidades específicas, saber: a avaliação diagnóstica, a formativa e a somativa.

\section{Avaliação Diagnóstica}

É aquela onde o professor deve manter a preocupação de saber quais são os conhecimentos prévios do aluno para analisar quais habilidades ou caminhos buscar para que seus alunos possam estar preparados para novas aprendizagens, evidenciando as especificidades de cada aluno. Esse tipo de avaliação corresponde à prevenção de um atraso de dificuldade na aprendizagem, 
colaborando e destacando suas aptidões de forma que possibilitem atingir um elevado índice de conhecimento, devendo explorar, identificar e adaptar-se perante suas competências e aprendizagens. A avaliação diagnóstica em linhas gerais dá ao professor a oportunidade de conhecer melhor os seus alunos e juntamente com eles estabelecer os caminhos a serem percorridos pela tomada de decisão inicial, com o intuito de atingir a aprendizagem.

\section{Avaliação Somativa}

Este tipo de avaliação, também chamada de classificatória tem como objetivo a visão geral dos conhecimentos de um aluno no fim de um período, ou de um curso. Busca avaliar os níveis de aproveitamento. Baseia-se em conteúdos de medida como provas, dissertações, trabalhos, enfim, classificam aqueles que atingiram e/ou não os objetivos esperados.

\section{Avaliação Formativa}

É de bastante importância, pois consiste a forma de como a função da vivência entre alunos e professores, notando as significativas aprendizagens trabalhadas durante este processo. $\mathrm{O}$ professor como mediador deve contextualizar problemas onde possa levar aos alunos maneiras de solucioná-los, estimulando suas competências sem esquecer que o professor deve esclarecer antes ao aluno o que se é esperado levando em conta sua própria auto - avaliação. Sabemos também que ela se fundamenta no construtivismo, onde há várias realidades que se atribuem a fenômenos no contexto em que vivem, possibilitando ao professor acompanhar e ajudar a aprendizagem dos seus alunos é fundamental um planejamento, elaborado com estratégias individuais, onde as dificuldades são percebidas. O empenho e responsabilização devem assim, partir tanto dos professores quanto dos alunos para um bom desempenho educacional; o professor em organizar suas propostas e os alunos em dedicarem-se numa efetiva disponibilidade diante de suas aprendizagens.

Estas concepções dão esclarecimentos a respeito das formas de avaliar. Quando esta passa a ser interiorizada pelo professor, o seu sucesso é notável. Outra coisa que evidenciamos é que a avaliação não pode ser confundida com a aplicação de "exames e provas" Luckesi (1996). Ou seja, avaliar para registrar notas não é o objetivo principal, pois mesmo que se deixe de existir exames o ato de avaliar sempre continuará a existir.

Ao referir-se ao ato de avaliar Luckesi (1996, p.67): "avaliar é um ato amoroso". Com essa afirmação o autor nos ínsita a introduzir em nossa prática a avaliação sendo como positiva, 
construtora e norteadora de caminhos. Destarte, cabe aos professores refletir sobre sua prática, fazer a sua autoavaliação e buscar mecanismos de avaliação que elevem a autoestima e libertem seus alunos da visão negativa que se tem sobre esta ação.

O referido trabalho foi realizado através de entrevista in lócus, onde pudemos ter o contato direto com a professora e o aluno entrevistado. Afim de melhor esclarecermos e adquirir mais conhecimentos, recorremos à revisão bibliográfica que apontou caminhos e a chegar às conclusões pertinentes sobre a avaliação e suas facetas. Isto possibilitou uma maior aproximação acerca da avaliação como um todo, propondo reflexões e tomada de decisões para que em nossa prática esta também possa acontecer como se propõe.

\section{RESULTADOS E DISCUSSÃO}

Classificar e rotular é o que mais encontramos na prática avaliativa de muitos educadores do país. Por muitas vezes fruto de um sistema que não oferece ao professor a liberdade de inovar e buscar uma nova forma de avaliar seus alunos. Entendemos que a avaliação deve dar e criar possibilidades e não tirar oportunidades. Abrir caminhos e traçar metas a se chegar. Observar os pressupostos que estão na prática de cada educador pela formação que receberam durante sua trajetória estudantil. A avaliação deixa marcas, assim sendo deve acontecer como um ato amoroso, positivo, estimulante. E construir a partir do erro é uma das formas mais plausíveis de avaliar.

Nessa direção, ao estudarmos a avaliação e como esta acontece, recorremos a vários autores que nos serviram como referencial, porém, nada melhor que o contato direto com os sujeitos para termos esclarecido como a avaliação acontece no dia-a-dia de professores. Para registrar e nos inteirarmos da prática, entrevistamos uma professora e um aluno da rede Municipal de Ensino do Município de Machados-PE. A professora atuante na turma do $5^{\circ}$ ano do ensino fundamental. Nesta sessão apresentaremos as entrevistas feitas (questões e respostas) e as discussões e conclusões que foram possíveis se obter por meio desta analise.

Ao entrevistarmos a professora e o aluno, fizemos em momentos diferentes e separados um do outro. O que é mais prazeroso em ver é que ambos entendem a avaliação como um processo de construção e que ela acontece tanto na prática da professora quanto na vivência do aluno de maneira unificada. Um corresponde ao outro de maneira que a parceria é notável. As respostas dadas por cada um pode nos nortear a cerca do que discutimos em sala e de como isto é prazeroso em ver. Nos surpreendemos em ver que a concepção de avaliação já está interiorizada em cada um (professora e aluno). Com isso, pudemos ver que a avaliação pode acontecer da forma como deve, sendo um 
processo e não um fim e que são poucos, mas são valiosos os professores que a tem desta forma. Algo percebível também é a falta de apoio que o professor ainda sofre, levando de certa maneira a trabalhar "escondido" fingindo atender ao que pede o sistema.

Nos quadros abaixo apontamos os dados coletados no processo da pesquisa:

\begin{tabular}{|c|c|}
\hline \multicolumn{2}{|c|}{ QUESTIONÁRIO - PROFESSOR } \\
\hline $\begin{array}{c}\text { QUESTÕES } \\
\end{array}$ & $\begin{array}{l}\text { RESPOSTAS } \\
\end{array}$ \\
\hline $\begin{array}{l}\text { 1.Em sua concepção, qual a importância da } \\
\text { avaliação da aprendizagem? }\end{array}$ & $\begin{array}{l}\text { De acordo com o programa (Alfabetizar com } \\
\text { Sucesso) adotado pelo município não se tem } \\
\text { êxito, pois um teste deixa de ter importância. } \\
\text { Busco avaliar meus alunos através das } \\
\text { atividades, trabalhos e apresentações em sala. }\end{array}$ \\
\hline $\begin{array}{l}\text { 2.Quais as expectativas criadas sobre o aluno } \\
\text { que está sendo avaliado? }\end{array}$ & $\begin{array}{l}\text { Que ele tenha compreensão, pois sem isso ele } \\
\text { não vai produzir e criar. }\end{array}$ \\
\hline $\begin{array}{l}\text { 3.Quais instrumentos avaliativos } \\
\text { aplicados, com freqüência, em seu fazer } \\
\text { docente? }\end{array}$ & $\begin{array}{l}\text { Trabalhos em grupo realizados em sala, testes } \\
\text { (não são obrigatórios, mas utilizo). Atividades } \\
\text { para casa e através dos questionamentos } \\
\text { levantados pelos alunos. }\end{array}$ \\
\hline $\begin{array}{l}\text { 4.Quais as principais contribuições que a } \\
\text { avaliação traz a aprendizagem? }\end{array}$ & A construção, pois estimula o indivíduo. \\
\hline $\begin{array}{l}\text { 5.Quais as intervenções adotadas para os } \\
\text { alunos que não atingem os resultados } \\
\text { esperados? }\end{array}$ & $\begin{array}{l}\text { Na escola se tem o reforço. Mas, busco } \\
\text { atividades diferenciadas, trabalhando as } \\
\text { necessidades deles. Intercalo atividades com } \\
\text { diferentes graus de dificuldade. }\end{array}$ \\
\hline $\begin{array}{l}\text { 6. Qual a concepção de avaliação contemplada } \\
\text { no Projeto Político Pedagógico da Escola? }\end{array}$ & $\begin{array}{l}\text { Não sei. Não existe transparência por parte da } \\
\text { escola. São feitas muitas cobranças em cima } \\
\text { do sistema, não existindo apoio da gestão e } \\
\text { coordenação. }\end{array}$ \\
\hline $\begin{array}{l}\text { 7.Em que momento você realiza a } \\
\text { autoavaliação? E qual a consequência dessa } \\
\text { ação em seu fazer docente? }\end{array}$ & $\begin{array}{l}\text { Ela é feita quando o aluno apresenta } \\
\text { dificuldades. Assim, busco outras maneiras } \\
\text { para chegar ao objetivo. Tem consequência } \\
\text { dolorosa pela falta de interesse dos alunos, } \\
\text { que causa-me a falta de estímulo. }\end{array}$ \\
\hline
\end{tabular}

Fonte: Quadro elaborado pelos pesquisadores a partir das respostas do participante realizado no dia 12-05-2015

\begin{tabular}{|l|l|}
\hline \multicolumn{2}{|c|}{ QUESTIONÁRIO - ALUNO } \\
\hline \multicolumn{1}{|c|}{ QUESTÕES } & \multicolumn{1}{c|}{ RESPOSTAS } \\
\hline 1. Para você, o que é avaliação? & $\begin{array}{l}\text { É uma coisa boa. Nas tarefas, relembrando os } \\
\text { assuntos. }\end{array}$ \\
\hline 2. Para quê serve a avaliação? & $\begin{array}{l}\text { Para saber se está bem nas matérias, tirar } \\
\text { notas boas para ser aprovado no fim do ano. }\end{array}$ \\
\hline 3. Como é que os professores avaliam vocês? & $\begin{array}{l}\text { Com atividades, com recursos para aprender } \\
\text { os conteúdos. Através de questionários orais e } \\
\text { escritos. }\end{array}$ \\
\hline $\begin{array}{l}\text { 4. Todos os professores avaliam do mesmo } \\
\text { jeito? Explique. }\end{array}$ & $\begin{array}{l}\text { Não. Os professores de antes, não utilizavam } \\
\text { a tecnologia na sala, era sempre através de }\end{array}$ \\
\hline
\end{tabular}




\begin{tabular}{|l|l|}
\hline & atividades. \\
\hline 5. Quando vocês são avaliados? & $\begin{array}{l}\text { No decorrer da semana, através de atividades, } \\
\text { trabalhos e sempre nos pede pra ter reforço } \\
\text { em casa. }\end{array}$ \\
\hline $\begin{array}{l}\text { 6. Você está satisfeito com o modo como é } \\
\text { feita a avaliação na escola? Comente. }\end{array}$ & $\begin{array}{l}\text { Sim. Porque é boa a forma como a professora } \\
\text { ensina e explica. }\end{array}$ \\
\hline
\end{tabular}

Fonte: Quadro elaborado pelas pesquisadoras a partir das respostas do participante realizado no dia 12-05-2015

\section{Considerações}

Ao considerar que a avaliação é um processo natural e que deve estar interiorizado pelo professor é possível estar seguro de que as leituras feitas puderam contribuir para se chegar ao objetivo esperado. Este olhar que tomamos a cerca da experiência com a professora e o aluno nos possibilitou reconhecer que a avaliação acontece sim de forma correta e que não são todos os professores que tem a visão de que ela é apenas um meio para se obtiver notas e classificar seus alunos.

Rever conceitos e tomar novas atitudes requer uma ação prática de todos que fazem parte do processo educacional. Por isso, pais, alunos, professores, gestores e coordenadores devem tomar consciência de que é possível avaliar sem oprimir e continuar na luta pela realização de algo que sonhamos a anos e que aos poucos vem acontecendo. Quanto mais pessoas tomarem consciência disto e inserirem em suas discussões a avaliação irá elevar a um patamar de total prioridade a avaliação, pois estamos praticando ela diariamente de maneira formal e/ou informal. O que almejamos é que esta discussão tome cada vez mais voz e produza a valorização do sujeito, que contribui de forma singular dentro de uma pluralidade que é a vida social.

\section{Referências}

CALDEIRA, Anna M. Salgueiro. Avaliação e processo de ensino aprendizagem. Presença Pedagógica, Belo Horizonte, v. 3, p. 53-61, set./out. 1997. . Ressignificando a avaliação escolar. In: Comissão Permanente de Avaliação Institucional: UFMG-PAIUB. Belo Horizonte: PROGRAD/UFMG, 2000. p. 122-129 (Cadernos de Avaliação, 3).

LUCKESI, Cipriano. Avaliação da aprendizagem escolar. 13. Ed. São Paulo: Cortez,2002. 